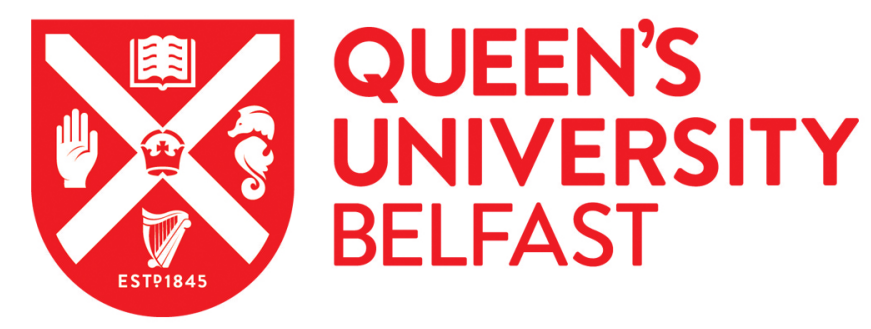

\title{
Cyclometalation via Carbon-Fluorine Bond Activation Induced by Silver Particles
}

Thomas, H., Wang, Y., Lorenzini, F., Coles, S. J., Horton, P. N., Marr, A. C., \& Saunders, G. C. (2017).

Cyclometalation via Carbon-Fluorine Bond Activation Induced by Silver Particles. Organometallics, 36(5), 960963. https://doi.org/10.1021/acs.organomet.6b00872

\author{
Published in: \\ Organometallics
}

Document Version:

Peer reviewed version

Queen's University Belfast - Research Portal:

Link to publication record in Queen's University Belfast Research Portal

\section{Publisher rights}

Copyright 2017 American Chemical Society.

This work is made available online in accordance with the publisher's policies. Please refer to any applicable terms of use of the publisher.

\section{General rights}

Copyright for the publications made accessible via the Queen's University Belfast Research Portal is retained by the author(s) and / or other copyright owners and it is a condition of accessing these publications that users recognise and abide by the legal requirements associated with these rights.

Take down policy

The Research Portal is Queen's institutional repository that provides access to Queen's research output. Every effort has been made to ensure that content in the Research Portal does not infringe any person's rights, or applicable UK laws. If you discover content in the Research Portal that you believe breaches copyright or violates any law, please contact openaccess@qub.ac.uk. 


\title{
Cyclometallation via Carbon-Fluorine Bond Activation Induced by Silver Particles
}

\author{
Hayden P. Thomas, ${ }^{\dagger}$ Yue-Ming Wang, ${ }^{\ddagger}$ Fabio Lorenzini, ${ }^{\ddagger}$ Simon J. Coles, ${ }^{\top}$ Peter N. Horton, ${ }^{\mp}$ \\ Andrew C. Marr ${ }^{*} \neq$ and Graham C. Saunders $*,+$ \\ ${ }^{\dagger}$ School of Science, University of Waikato, Hamilton 3240, New Zealand. \\ ‡ School of Chemistry and Chemical Engineering, Queen’s University Belfast, David Keir Building, Belfast BT9 5AG, \\ United Kingdom \\ I UK National Crystallographic Service, Chemical Crystallography Laboratory, School of Chemistry, University of \\ Southampton, University Road, Highfield, Southampton SO17 1BJ, United Kingdom.
}

\section{Supporting Information Placeholder}

\begin{abstract}
On treatment with either freshly-prepared silver nanoparticles or silver particles mechanochemically generated by stirring silver(I) oxide in dichloromethane, the complex $\left[\mathrm{Cp}^{*} \mathrm{IrCl}_{2}\left(\kappa \mathrm{C}-\mathrm{MeNC}_{3} \mathrm{H}_{2} \mathrm{NCH}_{2} \mathrm{C}_{6} \mathrm{~F}_{5}\right)\right]$ underwent a rapid and clean cyclometallation involving carbon-fluorine bond fission to afford the product $\left[\mathrm{Cp}^{*} \operatorname{IrCl}\left(\kappa \mathrm{C}^{2}-\right.\right.$ $\left.\left.\mathrm{MeNC}_{3} \mathrm{H}_{2} \mathrm{NCH}_{2} \mathrm{C}_{6} \mathrm{~F}_{4}\right)\right]$.
\end{abstract}

The activation of carbon-fluorine bonds by metal complexes has attracted much attention during the past two decades. ${ }^{1}$ Breaking these strong bonds is a considerable academic challenge. Interest in $\mathrm{C}-\mathrm{F}$ chemistry stems from the importance of fluorinated compounds in industry, and, in particular, their recent predominance in new pharmaceuticals. ${ }^{2}$ The $\mathrm{C}-\mathrm{F}$ bond has prime importance in the prevention of toxic responses to drug molecules. In addition, understanding the activation of cheap and readily available polyfluorinated compounds, such as perfluoroarenes, ${ }^{3}$ could facilitate the design of improved catalytic routes to fluorinated organic compounds. One strategy to overcome the thermodynamic problem of cleaving $\mathrm{C}-\mathrm{F}$ bonds is the use of intramolecular reactions. For geometric reasons these tend to be rapid, regiospecific and therefore high-yielding. A number of examples have been reported, 4 including those leading to cyclometallated products. 5 However, despite cyclometallation involving $\mathrm{C}-\mathrm{F}$ bond fission being first reported over 40 years ago, ${ }^{\mathrm{a}}$ it remains rare in comparison to cyclometallation involving $\mathrm{C}-\mathrm{H}$ bond fission, and a working knowledge of how to manipulate fluorinated organic compounds efficiently has yet to be achieved. Here we report an unexpected cyclometallation by $\mathrm{C}-\mathrm{F}$ bond fission occurring by the action of silver, either as nanoparticles or as particles generated mechanochemically from silver(I) oxide.

In an attempt to prepare $\left[\mathrm{Cp}^{*} \mathrm{IrCl}_{2}(\kappa \mathrm{C}\right.$ $\left.\left.\mathrm{MeNC}_{3} \mathrm{H}_{2} \mathrm{NCH}_{2} \mathrm{C}_{6} \mathrm{~F}_{5}\right)\right], \quad \mathbf{1},{ }^{6}$ by a one-pot synthesis, 1pentafluorobenzyl-3-methylimidazolium bromide was stirred in the presence of an excess of silver(I) oxide in dichloro- methane for $1 \frac{1}{2} \mathrm{~h}$ to generate the silver $\mathrm{NHC}$ reagent $\left[\mathrm{AgBr}\left(\kappa \mathrm{C}-\mathrm{MeNC}_{3} \mathrm{H}_{2} \mathrm{NCH}_{2} \mathrm{C}_{6} \mathrm{~F}_{5}\right)\right]$, and $\left[\mathrm{Cp}^{*} \mathrm{IrCl}_{2}\right]_{2}$ was then added. Surprisingly, after stirring for a further $4 \mathrm{~h}$., the cyclometallated compound, 2, was obtained (Scheme 1) and isolated in $79 \%$ yield. The identity of $\mathbf{2}$ was confirmed by a single-crystal X-ray diffraction study (Figure 1), with which other characterizing data are entirely consistent (see "Supporting Information"). In particular, the mass spectrum displays $[\mathrm{M}-\mathrm{Cl}]^{+}$and the ${ }^{19} \mathrm{~F}$ NMR spectrum displays four resonances with equal integration at $\delta$-114.0, -147.7, -158.4 and 165.3 .

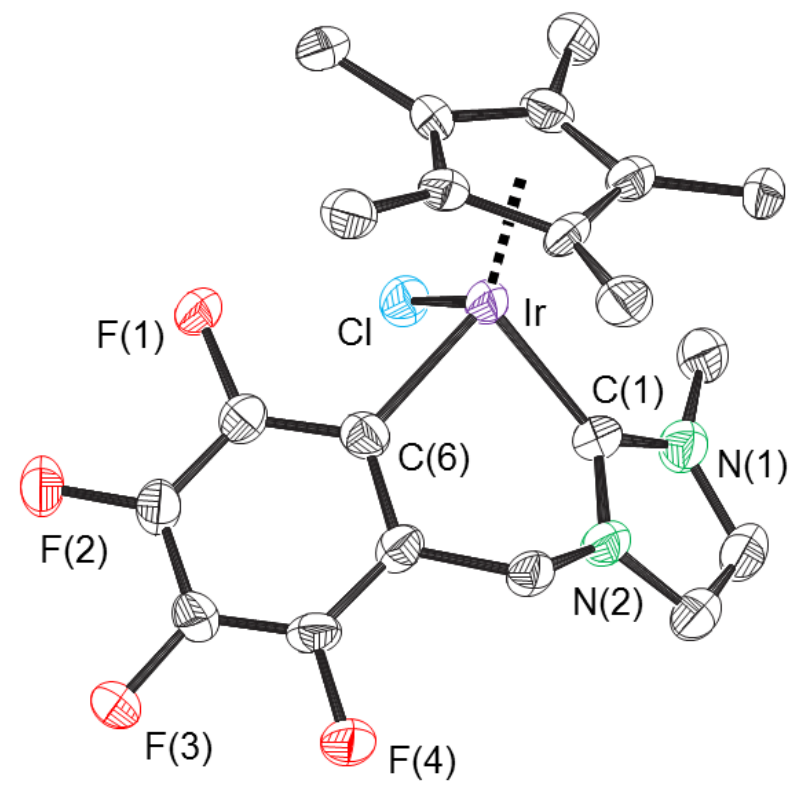

Figure 1. Molecular structure of 2. Thermal ellipsoids represent $50 \%$ probability. Hydrogen atoms have been omitted for clarity. Selected bond distances $(\AA)$ and angles $\left(^{\circ}\right)$ : $\mathrm{CP}^{*}-\mathrm{Ir}$ 1.844(9), Ir-Cl 2.444(2), Ir-C(1) 2.015(7), Ir-C(6) 2.069(6), $\mathrm{Cp}^{*}-\mathrm{Ir}-\mathrm{Cl}$ 124.3(2), Cp*-Ir-C(1) 127.7(3), Cp*-Ir-C(6) 128.1(3), $\quad \mathrm{Cl}-\mathrm{Ir}-\mathrm{C}(1) \quad 89.8(2), \quad \mathrm{Cl}-\mathrm{Ir}-\mathrm{C}(6) \quad 88.2(2)$, $\mathrm{C}(1)-\mathrm{Ir}-\mathrm{C}(6) 85.7(3)$. 
Previous studies ${ }^{6}$ and subsequent syntheses of $\mathbf{1}$, indicated that the $\mathrm{C}-\mathrm{F}$ bond activation does not occur with the imidazolium salt or the silver NHC compound. Consequently the reaction occurs only when the NHC is coordinated to iridium. Heating a solution of $\mathbf{1}$ in chloroform at $70^{\circ} \mathrm{C}$ for 10 h. induced no reaction and so a spontaneous reaction can be discounted. Neither did reaction occur on treatment of 1 with $\left[\mathrm{AgBr}\left(\kappa \mathrm{C}-\mathrm{MeNC}_{3} \mathrm{H}_{2} \mathrm{NCH}_{2} \mathrm{C}_{6} \mathrm{~F}_{5}\right)\right]$. However, 2 was afforded when 1 was added to a suspension of silver(I) oxide in dichloromethane that had previously been stirred for $2 \mathrm{~h}$. Base-induced cyclometallation in complexes of nonfluorinated benzyl-substituted ligands has been reported previously.7 Indeed cyclometallation induced by silver(I) oxide has recently been reported for a series of piano stool ruthenium NHC complexes. ${ }^{8}$ However, an in situ NMR study indicated that there is no reaction on treatment of 1 with triethylamine. Since the latter reagent would generate hydroxide ions under the hydrous conditions of the experiment, their involvement, either as base or reducing agent, 9 can be ruled out. Devising a mechanism for the reaction to occur between $\mathbf{1}$ and silver(I) oxide is problematic: a carbon atom undergoes a formal reduction from +1 to -1 on $\mathrm{C}-\mathrm{F}$ bond fission and $\mathrm{Ir}-\mathrm{C}$ bond formation, but there is no corresponding oxidation. Silver(I) oxide has been found to react with a related rhodium NHC complex, but the reaction involves intramolecular nucleophilic attack by an oxide or a related species, and the oxygen atom is retained in the product. $^{10}$ Clearly this pathway is not applicable to the reaction between 1 and silver(I) oxide.

Scheme 1. Reaction between Complex 1 and Silver Particles
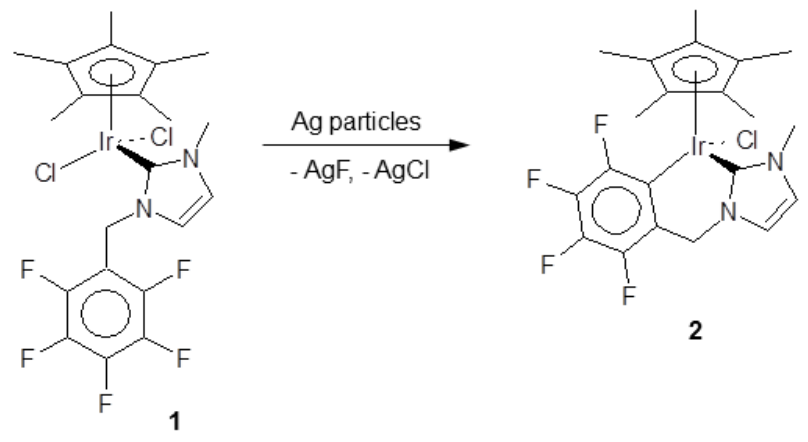

Since silver(I) oxide is unlikely to be directly responsible for cyclometallation, the possible involvement of elemental silver was considered. In this case the reduction of the carbon atom would be matched by oxidation of two silver atoms to afford silver(I) chloride and fluoride. The hypothesis was supported by the identification of both these by-products in the residue (see "Supporting Information"). Furthermore, an in situ NMR study found that when $\mathbf{1}$ was treated with silver nanoparticles, prepared from silver nitrate and triethylamine, ${ }^{11} 2$ was formed rapidly and cleanly. The generation of silver nanoparticles when an excess of silver(I) oxide was used to prepare silver NHC compounds has been noted as an interesting observation, ${ }^{12}$ but no explanation was suggested, and no subsequent investigation was undertaken.

Although no difference between a fresh sample of commercial silver(I) oxide (Sigma Aldrich) and a sample that had been stirred in dichloromethane for $2 \mathrm{~h}$. was discernible visibly or by SEM (Figure 2), EDS and qualitative analytical tests $^{13}$ revealed that the former was silver(I) oxide, whereas the latter was predominantly elemental silver (see "Supporting Information"). Silver(I) oxide is known to undergo autocatalytic thermal decomposition to silver and oxygen, ${ }^{14}$ but this decomposition route is not consistent with the reaction conditions. Whilst most silver salts are well known to be photosensitive, to our knowledge there are no reports of light causing the decomposition of silver(I) oxide, although in the presence of aqueous hydroxide, in which silver hydroxide is formed, slow, light-induced deposition of elemental silver has been reported. 15 Decomposition by ballmilling has been reported recently, ${ }^{16}$ although the decomposition, monitored by powder X-ray diffraction, was slow, taking more than 9o h. to reach completion. Furthermore, the heat generated by the technique may have contributed to the decomposition. It is improbable that a reaction of silver(I) oxide with dichloromethane yields silver and not also silver chloride, which would have been detected in the sample. Consequently silver(I) oxide decomposition by the mechanical action of stirring was considered. The standard Gibbs free energy, $\Delta \mathrm{G}_{\mathrm{f}}^{\mathrm{\theta}}$, for silver(I) oxide is only $-2.7 \mathrm{kcal}$ $\mathrm{mol}^{-1},{ }^{17}$ and it is plausible that the collision of stirred particles imparts sufficient energy. The facile nature of the decomposition was confirmed by grinding $c a$. $0.2 \mathrm{~g}$ of silver oxide manually for 15 mins., which afforded a ca. 1:1 mixture of silver and silver(I) oxide, and by stirring ca. $0.2 \mathrm{~g}$ of silver oxide, in the absence of solvent, for 2 h., which produced ca. 90\% of elemental silver. Further evidence for this reaction is provided by the common appearance of silver on the thread of bottles of silver(I) oxide, which is formed by the mechanical action of screwing and unscrewing the top. It is hard to reconcile the facile decomposition on stirring with the slow decomposition observed on ball-milling, ${ }^{16}$ but the different nature of the silver(I) oxide particles and the quantities used (ca. $0.2 \mathrm{~g} c f .9 .75 \mathrm{~g}$ ) may account for the observations.

Figure 2. SEM images of a commercial (Sigma Aldrich) sample of silver(I) oxide as purchased ((a) and (c)) and after stirring in dichloromethane for $2 \mathrm{~h}$. ((b) and (d)).
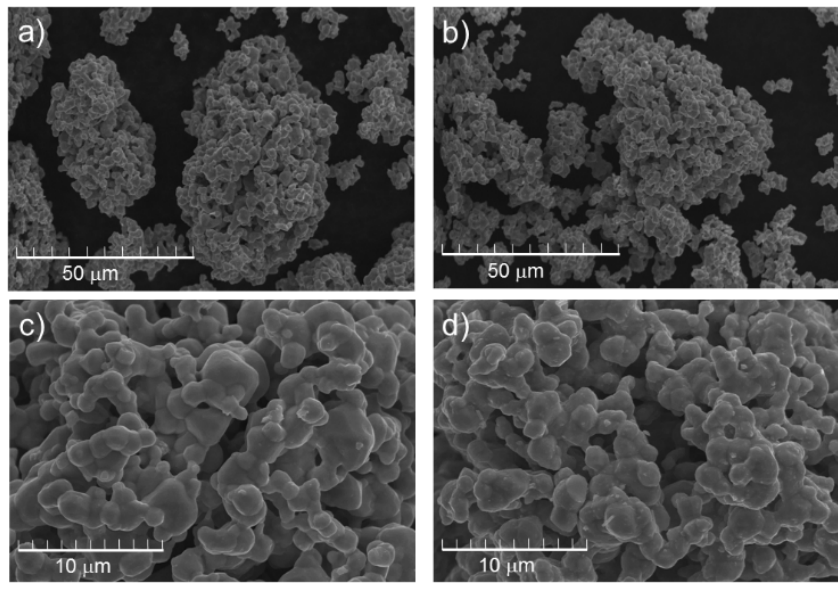

The regiospecificity of the reaction between $\mathbf{1}$ and silver particles suggests that $\mathrm{C}-\mathrm{F}$ bond fission is not the initial step, because the para position is typically the most activated position in pentafluorophenyl compounds. A possible mechanism involves reduction of iridium and abstraction of chloride giving an anionic iridium(I) center, which performs nucleophilic attack on an ortho carbon atom of the phenyl ring. Although it is unlikely that bulk silver metal is capable of reducing $\mathbf{1}$, silver nanoparticles are known to display a sizedependent reduction potential that is lower than that of the 
bulk metal. ${ }^{18}$ In support of this mechanism the reaction between $\mathbf{1}$ and zinc powder in the presence of aqueous hydrochloric acid produced 2, although significantly less cleanly than observed with silver particles.

In summary, silver particles, generated by simply stirring silver(I) oxide in dichloromethane, induce a rapid and clean cyclometallation reaction in $\left[\mathrm{Cp}^{*} \mathrm{IrCl}_{2}(\kappa \mathrm{C}\right.$ $\mathrm{MeNC}_{3} \mathrm{H}_{2} \mathrm{NCH}_{2} \mathrm{C}_{6} \mathrm{~F}_{5}$ )], which occurs via regiospecific carbon-fluorine bond activation.

\section{ASSOCIATED CONTENT}

\section{Supporting Information}

Experimental procedures, characterizing data, spectra and associated figures

Crystallographic data for 2

\section{AUTHOR INFORMATION}

\section{Corresponding Authors}

*a.marr@qub.ac.uk

* g.saunders@waikato.ac.nz

\section{Author Contributions}

†, $\ddagger$ HPT, Y-MW, FL, ACM and GCS contributed equally, except for the structural determination of 2 , which was performed by $\uparrow$ SJC and PNH.

\section{Notes}

The authors declare no competing financial interests.

\section{ACKNOWLEDGMENT}

We thank Queen's University Belfast, the University of Waikato, and the GRAIL (Grant agreement no: 613667), project co-financed by the European Commission under the $7^{\text {th }}$ Framework Programme, for financial assistance, and the EPSRC UK National Crystallography Service at the University of Southampton for the collection of the crystallographic data. ${ }^{19}$ We thank one reviewer for drawing our attention to the ability of hydroxide to act as a reducing agent.

\section{REFERENCES}

(1) (a) Kiplinger, J. L.; Richmond, T. G.; Osterberg, C. E. Chem. Rev. 1994, 94, 373-431. (b) Ahrens, T.; Kohlmann, J.; Ahrens, M.; Braun, T. Chem. Rev. 2015, 115, 931-972. (c) LaBerge, N. A.; Love, J. A. Topics Organomet. Chem. 2015, 52, 55-111.

(2) Wang, J.; Sánchez-Roselló, M.; Aceña, J. L.; del Pozo, C.; Sorochinsky, A. E.; Fustero, S.; Soloshonok, V. A.; Liu, H. Chem. Rev., 2014, 114, 2432-2506.

(3) (a) Aizenberg, M.; Milstein, D. J. Am. Chem. Soc. 1995, 117, 8674-8675. (b) Reade, S. P.; Mahon, M. F.; Whittlesey, M. K. J. Am. Chem. Soc. 2009, 131, 1847-1861.

(4) For selected examples see (a) Park, S.; Pontier-Johnson, M.; Roundhill, D. M. J. Am. Chem. Soc. 1989, 111, 3101-3103. (b) Atherton, M. J.; Fawcett, J.; Holloway, J. H.; Hope, E. G.; Karaçar, A.; Russell, D. R.; Saunders, G. C. J. Chem. Soc., Chem. Commun. 1995, 191-192. (c) Hughes, R. P.; Lindner, D. C.; Rheingold, A. L.; Yap, G. P. A. Organometallics 1996, 15, 5678-5686. (d) Bellabarba. R. M.; Saunders, G. C.; Scott, S. Inorg. Chem. Commun. 2002, 5, 15-18. (e) Villanueva, L.;
Arroyo, M.; Bernès, S.; Torrens, H. Chem. Commun. 2004, 1942-1943. (f) Albers, T.; Edwards, P. G. Chem. Comm. 2007, 858-86o.

(5) For selected examples see (a) Bruce, M. I.; Gardner, R. C. F.; Goodall, B. L.; Stone, F. G. A.; Doedens, R. J.; Moreland, J. A. J. Chem. Soc., Chem. Comm. 1974, 185-186. (b) Bruce, M. I.; Goodall, B. L.; Sheppard, G. L.; Stone, F. G. A. J. Chem. Soc. Dalton Trans. 1975, 591595. (c) Bruce, M. I.; Gardner, R. C. F.; Stone, F. G. A. J. Chem. Soc., Dalton Trans. 1976, 81-89. (d) Richmond, T. G.; Osterberg, C. E.; Arif, A. M. J. Am. Chem. Soc. 1987, 109, 8091-8092. (e) Anderson, C. M.; Puddephat, R. J.; Ferguson, G.; Lough, A. J. J. Chem. Soc., Chem. Comm. 1989, 1287-1288. (f) Anderson, C. M.; Crespo, M.; Ferguson, G.; Lough, A. J.; Puddephat, R. J. Organometallics 1992, 11, 1177-1181. (g) Crespo, M.; Martinez, M.; Sales, J. Organometallics 1993, 12, 42974304. (h) Perera, S. D.; Shaw, B. L.; Thornton-Pett, M. Inorg. Chim. Acta 1995, 233, 103-107. (i) López, O.; Crespo, M.; Font-Bardia, M.; Solans, X. Organometallics 1997, 16, 1233-1240. (j) Li, X.; Sun, H.; Yu, F.; Flörke, U.; Klein, H.-F. Organometallics 20o6, 25, 4695-4697. (k) Keyes, L.; Sun, A. D.; Love, J. A. Eur. J. Org. Chem. 2011, 3985-3994.

(6) McGrandle, S. J.; Saunders, G. C. J. Fluorine Chem. 2005, 126, $451-455$.

(7) For selected examples see: (a) Fernandez, S.; Pfeffer, F.; Ritleng, V.; Sirlin, C. Organometallics 1999, 18, 2390-2394. (b) Davies, D. L.; Al-Duaij, O.; Fawcett, J.; Giardiello, M.; Hilton, S. T.; Russell, D. R. Dalton Trans. 2003, 4132-4138.

(8) Schleicher, D.; Tronnier, A.; Leopold, H.; Borrmann, H.; Strassner, T. Dalton Trans. 2016, 45, 3260-3263.

(9) Sawyer, D. T.; Roberts, J. L., Jr. Acc. Chem. Res. 1988, 21, 469476.

(10) Pachal, S. R.; Saunders, G. C.; Weston, J. K. Inorg. Chim. Acta 2013, 394, 558-562.

(11) Wu, J.-T.; Hsu, S. L.-C. J. Nanopart. Res. 2011, 13, 3877-3883.

(12) Lee, C. K.; Vasam, C. S.; Huang, T. W.; Wang, H. M. J.; Yang, R. Y.; Lee, C. S.; Lin, I. J. B. Organometallics 2006, 25, 3768-3775.

(13) Vogel, A. I. Textbook of macro and smimicro qualitative inorganic analysis; Longmans, Green \& Co., London, 1937.

(14) (a) Lewis, G. N. Proc. Am. Acad. Arts Sci. 1905, 40, 719-733. (b) Garner, W. E.; Reeves, L. W. Trans. Faraday Soc. 1954, 254-26o. (c) Herley, P. J.; Prout, E. G. J. Am. Chem. Soc. 196o, 82, 1540-1543.

(15) Dirkse, T. P.; Vander Hart, D.; Vriesenga, J. J. Inorg. Nucl. Chem. 1965, 27, 1779-1786.

(16) Khayati, G. R.; Janghorban, K. Trans. Nonferrous Met. Soc. China 2013, 23, 1520-1524.

(17) Aylard, G. H.; Findlay, T. J. V. SI Chemical Data, $5^{\text {th }}$ ed.; John Wiley \& Sons, 2002.

(18) (a) Plieth, W. J. J. Phys. Chem. 1982, 86, 3166-3170. (b) Ivanova, O. S.; Zamborini, F. P. J. Am. Chem. Soc. 2010, 132, 70-72. (c) Mikhlin, Y. L.; Vishnyakova, E. A.; Romanchenko, A. S.; Saikova, S. V.; Likhatski, M. N.; Larichev, Y. V.; Tuzikov, F. V.; Zaikovskii, V. I.; Zharkov, S. M. Appl. Surf. Sci. 2014, 297, 75-83.

(19) Coles, S. J.; Gale, P. A. Chem. Sci. 2012, 3, 683-689.

For table of contents only:

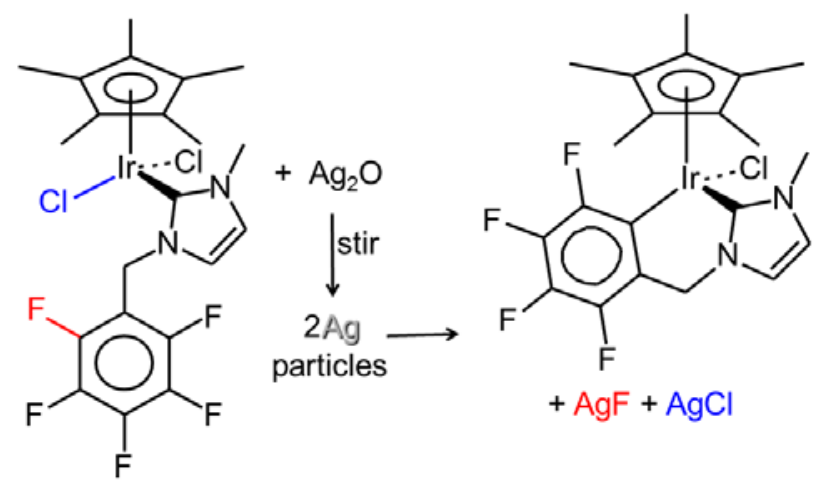

